\title{
A novel highly specialized functional flap: omohyoid inferior belly muscle
}

\author{
Gerado Muñoz-Jimenez, Jose E. Telich-Tarriba, Damian Palafox-Vidal, Alexander Cardenas-Mejia \\ Plastic and Reconstructive Surgery Division, Hospital General "Dr. Manuel Gea González", Postgraduate Division of the Medical \\ School, Universidad Nacional Autonoma de Mexico, Mexico City 14080, Mexico.
}

Correspondence to: Dr. Alexander Cardenas-Mejia, Plastic and Reconstructive Surgery Division, Hospital General “Dr. Manuel Gea González", Postgraduate Division of the Medical School, Universidad Nacional Autonoma de Mexico, Calzada de Tlalpan 4800, Mexico City 14080, Mexico. E-mail: alexcardenas@hotmail.com

\begin{abstract}
How to cite this article: Muñoz-Jimenez G, Telich-Tarriba JE, Palafox-Vidal D, Cardenas-Mejia A. A novel highly specialized functional flap: omohyoid inferior belly muscle. Plast Aesthet Res 2018;5:14. http://dx.doi.org/10.20517/2347-9264.2018.04
\end{abstract}

Received: 23 Jan 2018 First Decision: 9 Mar 2018 Revised: 12 Mar 2018 Accepted: 26 Mar 2018 Published: 23 Apr 2018

Science Editor: Raúl González-García Copy Editor: Jun-Yao Li Production Editor: Cai-Hong Wang

\begin{abstract}
Aim: There is no previous description on the anatomy of the inferior belly of the omohyoid muscle. This muscle has specific morphological characteristic that make it appealing when solving specialized reconstructive problems. Our objective is to describe the microsurgical anatomy of the inferior belly from the omohyoid muscle.
\end{abstract}

Methods: Supraclavicular bilateral dissection in 5 anatomic models (fresh human cadavers). Measurements were taken with a millimetric caliper. Statistical analysis was performed with measures of central tendency.

Results: Eight muscles were dissected in 5 anatomic models. Average dimensions were: $93 \mathrm{~mm}$ long, $12 \mathrm{~mm}$ wide, and $7.5 \mathrm{~mm}$ thickness. The vascular pedicles showed great anatomical variability. In 2 flaps (1 model) irrigation came exclusively from transverse cervical vessels, in the remaining models the pedicles came directly from the subclavian vessels; 2 flaps had an accessory minor pedicle from the transverse cervical vessels. The diameter of all vascular pedicles was less than $0.8 \mathrm{~mm}$, with an average length of $22.3 \mathrm{~mm}$. The nerve pedicle came from ansa cervicalis in all flaps, with an average length of $27.8 \mathrm{~mm}$.

Conclusion: Based on the findings we conclude that omohyoid muscle could be a reconstructive option when small functional flaps are required, such as facial reanimation surgery, sphincters, ptosis and vocal cord reconstruction, and blink restoration surgery although more anatomical studies are required to determine the microsurgical feasibility, excursion and strength of the muscle, and axonal load in this new myofunctional flap.

Keywords: Neck muscles, free tissue flaps, cadaver, models, anatomic, supermicrosurgery, infrahyoid muscles, omohyoid muscle

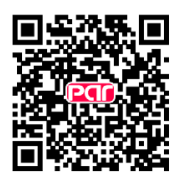




\section{INTRODUCTION}

The infrahyoid muscles are a group of paired strap-like muscles that include the thyrohyoid, sternothyroid, sternohyoid and the omohyoid. The omohyoid muscle is a digastric structure with an inferior belly originated in the scapula, a central tendon and a superior belly that inserts in the inferior border of the hyoid bone. Previous authors have described the gross and microsurgical anatomy of the infrahyoid muscles at length, however, the inferior belly of the omohyoid has remained largely ignored ${ }^{[1-8]}$.

The infrahyoid muscles' blood supply has been found to arise from the superior and inferior thyroid arteries, and the sternal branch of the internal thoracic artery; nevertheless, most authors have limited their investigations to the omohyoid's superior belly ${ }^{[1-3]}$. The ansa cervicalis has been found to present many variants in the terminal branches that innervate the strap muscles, but as of today there is no description on the branches directed to the inferior belly of the omohyoid muscle ${ }^{[4]}$.

Several descriptions on the use of the infrahyoid muscles for reconstruction of the tongue, larynx, esophagus and the vocal cords have been published, however it should be noted that most surgeons avoid the inclusion of the inferior belly of the omohyoid muscle in their flaps due to its distance from the site to be reconstructed ${ }^{[5-10]}$.

The inferior belly of the omohyoid muscle possesses appealing characteristics that may allow it to serve as a specialized functional flap, such as serving a noncritical function (easily performed by the rest of the infrahyoid muscles), and possessing small dimensions that allow for functional reconstruction in small areas; however, its potential use as a free flap has never been studied.

The objective of this work is to describe the surgical morphology of the inferior belly of the omohyoid muscle.

\section{METHODS}

Fresh human cadavers were used for this study; standardized dissections were conducted to establish the anatomical characteristics of the inferior belly of the omohyoid muscle.

Approval by the institutional ethics board was received. Data recorded included patients' demographic characteristics; history for trauma, or surgical procedures on the neck; muscle belly dimensions from its origin in the scapula to the central tendon; length of the vascular and nerve pedicle from its proximal dissection to the point of its emergence in the muscle fibers.

\section{Statistical analysis}

Descriptive analyses of patient demographic and clinical characteristics were performed. Continuous variables are expressed in central tendency measures, categorical values are presented as percentages.

\section{Cadaveric dissection}

A supraclavicular incision was performed following the contour of the sternocleidomastoid muscle. Subplatysmal flaps were elevated to expose the strap muscles and the sternocleidomastoid muscle. The sternocleidomastoid muscle is retracted laterally to expose of the omohyoid muscle.

The ansa cervicalis and the vascular pedicles were identified and dissected from their origin to the point of entry of the muscle belly; finally, the inferior muscle belly was extracted by disinserting it from the scapular surface and transecting the central tendon.

\section{RESULTS}

Five male anatomic models were studied (range 18 to 65 years), 2 muscles were discarded due to previous 


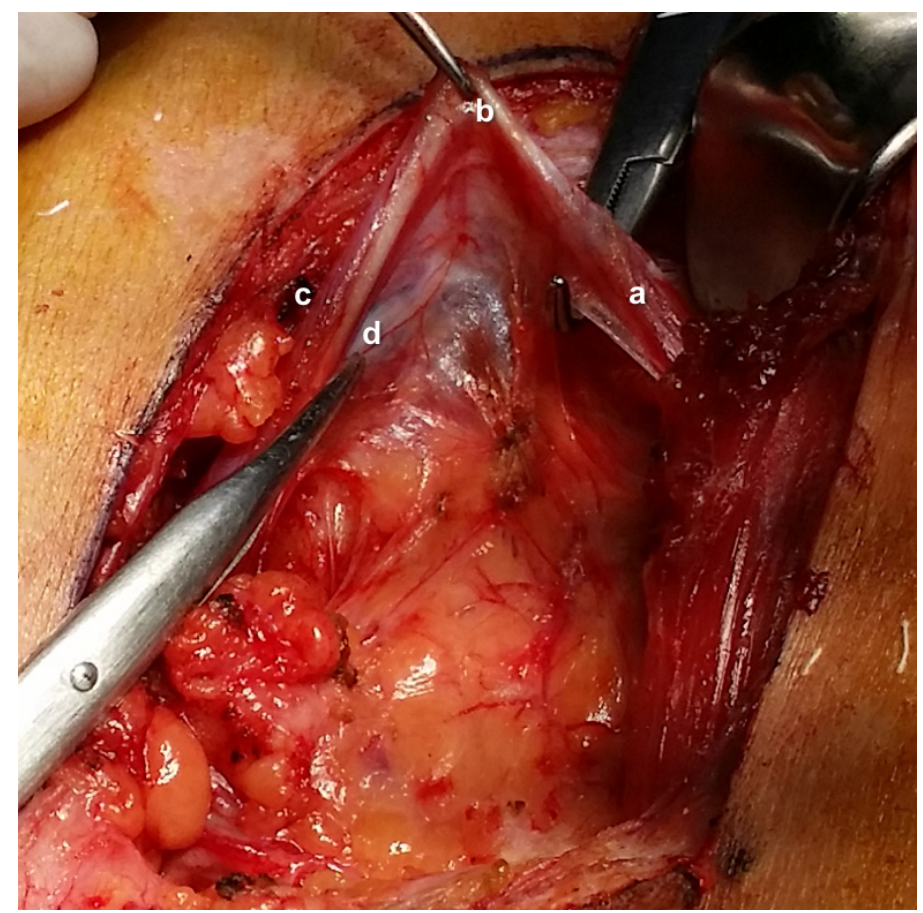

Figure 1. Anatomic dissection of the inferior belly of the omohyoid muscle. a: superior belly; b: central tendon; c: inferior belly; d: vascular pedicle

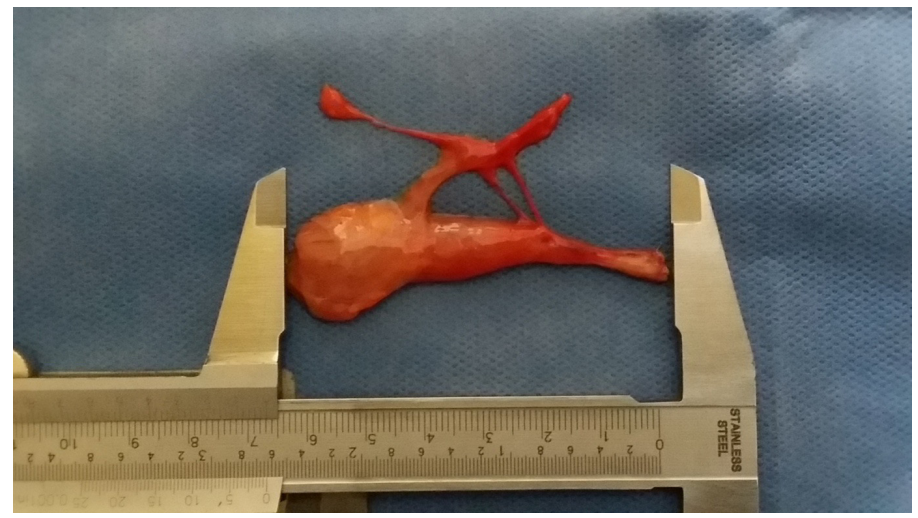

Figure 2. Muscle appearance after extraction

surgical procedures in 2 heminecks, resulting in a total of 8 muscle bellies studied. Figure 1 shows an example of the dissection area.

Average dimensions for the muscle belly were $93 \mathrm{~mm}$ long (range 67-110), $12 \mathrm{~mm}$ wide (range 6-20), and 7.5 $\mathrm{mm}$ thickness (range 6-12). The vascular pedicle had a mean length of $22.3 \mathrm{~mm}$ and a diameter of $0.8 \mathrm{~mm}$, the distance between the central tendon and the point where the pedicle entered the muscle fibers was 27.2 $\mathrm{mm}$; the ansa cervicalis' branch to inferior belly had a mean length of $27.8 \mathrm{~mm}$, it ran parallel to the muscle belly in all cases [Table 1]. Figure 2 shows an example of the muscles dissected.

Several anatomical variations were found: a minor vascular pedicle from the transverse cervical vessels in 2 flaps; in 1 model the artery arose from the transverse cervical vessels, while in the rest of the cases it derived from the subclavian vessels; 1 model lacked a central tendon. 
Table 1. Anatomic characteristics of the inferior belly of the omohyoid muscle

\begin{tabular}{|c|c|c|c|c|c|c|c|c|c|c|c|}
\hline \multirow[t]{2}{*}{ Model } & \multicolumn{2}{|c|}{ \# 1} & \multicolumn{2}{|c|}{ \# 2} & \multicolumn{2}{|c|}{ \# 3} & \multicolumn{2}{|c|}{ \#4 } & \multicolumn{2}{|c|}{ \# 5} & \multirow[t]{2}{*}{ Mean } \\
\hline & Left & Right & Left & Right & Left & Right & Left & Right & Left & Right & \\
\hline Vascular pedicle length & 15 & 17 & 28 & - & 13 & 21 & 23 & - & 20 & 42 & 22.3 \\
\hline Nerve length & 46 & 17 & 37 & - & 26 & 21 & 31 & - & 25 & 20 & 27.8 \\
\hline Flap length & 67 & 90 & 85 & - & 110 & 100 & 84 & - & 100 & 110 & 93.2 \\
\hline Flap width & 20 & 16 & 16 & - & 6 & 11 & 11 & - & 12 & 11 & 12.8 \\
\hline Flap thickness & 8 & 7 & 6 & - & 6 & 7 & 7 & - & 9 & 12 & 7.7 \\
\hline Tendon-Pedicle distance & 19 & 19 & 27 & - & \multicolumn{2}{|c|}{ No central tendon } & 25 & - & 75 & 53 & 27.2 \\
\hline Source vessel & SC & SC & SC & - & SC & $\mathrm{SC}$ & $\mathrm{SC}$ & - & $\mathrm{TC}$ & $\mathrm{TC}$ & \\
\hline Main nerve & $A C$ & $A C$ & $A C$ & - & $A C$ & $A C$ & $A C$ & - & $A C$ & $A C$ & \\
\hline
\end{tabular}

All measurements are expressed in millimeters $(\mathrm{mm})$. SC: subclavian artery; TC: transverse cervical artery; AC: ansa cervicalis

\section{DISCUSSION}

Our work represents the first time an anatomical study focused on the morphology of the inferior belly of the omohyoid muscle and its potential use as a free flap has been performed.

Our results show that the inferior belly is a small and thin muscle, with average measures of $93 \mathrm{~mm} \times 12 \mathrm{~mm}$ $\times 7.5 \mathrm{~mm}$, a trait that could prove to be advantageous, especially in facial reconstruction. The short length of the muscle's belly might raise concern about its contractile capacity and usefulness as a functional flap; however the senior author of this paper has observed that the muscle presents a nice range of motion when subjected to transoperatory neurostimulation during procedures for brachial plexus injury [Video 1].

Previous anatomical studies have described that the strap muscles present high morphological variability ${ }^{[2]}$, and we found that the inferior belly of the omohyoid muscle is no exception: a minor pedicle from the transverse cervical vessels was found in 2 cases, and 1 case in which the main pedicle came from the transverse cervical artery, in lieu of the subclavian artery.

The vascular pedicle of the inferior belly presents anatomical characteristics that may hinder its widespread use, mainly the presence of a short and narrow pedicle $(22.3 \mathrm{~mm} \times 0.8 \mathrm{~mm})$, nevertheless, the use of vein grafts and supermicrosurgery might help overcome the problem. Our results show that the inferior belly of the omohyoid muscle is innervated by the ansa cervicalis, and that it is relatively short as well, with a mean length of $27.8 \mathrm{~mm}$, however this limitation could be solved in a simple manner by using nerve autografts.

In conclusion, as microsurgical techniques and anatomical understanding of our body have expanded in the last decade, multiple new flaps have been described; the use of supermicrosurgery has further pushed boundaries and now vascular anastomosis in structures with a diameter minor to $0.8 \mathrm{~mm}$ are possible. This anatomical study of the inferior belly of the omohyoid muscle proposes its use in reconstructive procedures that require a small myofunctional flap such as facial reanimation surgery, sphincter reconstruction, vocal cord reconstruction, and blink restoration surgery.

\section{DECLARATIONS}

\section{Authors' contributions}

Anatomical model dissection, data acquisition and analysis: Muñoz-Jimenez G

Data analysis, paper writing, editing and translation: Telich-Tarriba JE, Palafox-Vidal D

Project supervisor and anatomical model dissection: Cardenas-Mejia A

\section{Data source and availability}

Anatomical models were obtained from the "Institute de Ciencias Forenses" in Mexico City. Raw data on measurements can be obtained by contacting Dr. Alexander Cardenas-Mejia directly. 


\section{Financial support and sponsorship}

None.

\section{Conflicts of interest}

Part of the work was presented at the 13th International Facial Nerve Symposium, August 3/6th 2017, Los Angeles CA, USA. The authors have no conflicts of interest to disclose.

\section{Patient consent}

Not applicable.

\section{Ethics approval}

This work received approval by the institutional ethics board.

\section{Copyright}

(c) The Author(s) 2018.

\section{REFERENCES}

1. Görmüs G, Bayramoğlu A, Aldur MM, Celik HH, Maral T, Sargon MF, Demiryürek D, Aksit MD. Vascular pedicles of infrahyoid muscles: an anatomical study. Clin Anat 2004;17:214-7.

2. Meguid EA, Agawany AE. An anatomical study of the arterial and nerve supply of the infrahyoid muscles. Folia Morphol (Warsz) 2009;68:233-43.

3. Remmert S, Meyer S, Majocco A. Der neurovaskuläre infrahyoidale Muskelfaszienlappen. Anatomisch topographische Untersuchung der Innervation und Gefäßversorgung. Ann Anat 1998;180:281-7. (in German)

4. Loukas M, Thorsell A, Tubbs RS, Kapos T, Louis RG Jr, Vulis M, Hage R, Jordan R. The ansa cervicalis revisited. Folia Morphol (Warsz) 2007;66:120-5.

5. Wang HS, Shen JW. Preliminary report on a new approach to the reconstruction of tongue. Acta Acud Med Prim Shanghai 1980;7:256-9.

6. Lockhart R, Menard P, Chout P, Favre-Dauvergne E, Berard P, Bertrand JC. Infrahyoid myocutaneous flap in reconstructive maxillofacial cancer and trauma surgery. Int J Oral Maxillofac Surg 1998;27:40-4.

7. Windfuhr JP, Remmert S. Infrahyoid myofascial flap for tongue reconstruction. Eur Arch Otorhinolaryngol 2006;263:1013-22.

8. Mirghani H, Meyer G, Hans S, Dolivet G, Périé S, Brasnu D, Guily JL. The musculocutaneous infrahyoid flap: surgical key points. Eur Arch Otorhinolaryngol 2012;269:1213-7.

9. Gangloff P, Deganello A, Lacave ML, Verhaeghe JL, Lapeyre M, Maire F, Phulpin B, Guillemin F, Dolivet G. Use of the infra hyoid musculo-cutaneous flap in soft palate reconstruction. Eur J Surg Oncol 2006;32:1165-9.

10. Dolivet G, Gangloff P, Sarini J, Ton Van J, Garron X, Guillemin F, Lefebvre JL. Modification of the infra hyoid musculo-cutaneous flap. Eur J Surg Oncol 2005;31:294-8. 